\title{
Management of pneumothorax in adults with cystic fibrosis
}

\author{
ARL PENKETH, RK KNIGHT, MARGARET E HODSON, JC BATTEN \\ From the Cardiothoracic Institute and Brompton Hospital, London
}

ABSTRACT The histories of 243 adults with cystic fibrosis were reviewed; 46 had experienced one or more spontaneous pneumothoraces $(18.9 \%)$, and seven had died of this complication. There was a high incidence of recurrence on the same side after conservative management $(50 \%)$ or intercostal drainage (55.2\%). Prolonged intercostal drainage was associated with a high mortality. One-third of patients required surgical treatment. Twenty thoracotomies were performed. Three of these patients died but only two of the 17 survivors had recurrences. Severe airflow obstruction was not a contraindication to surgery. A plan of management for future cases is outlined.

There is a high incidence of pneumothorax in patients with cystic fibrosis, and it is an important cause of both morbidity and mortality. ${ }^{1-4}$ Pneumothorax occurs mainly in those patients with advanced disease, severe airflow obstruction, and chronic Pseudomonas aeruginosa infection. ${ }^{15}$ All the methods available for treatment of pneumothorax have been used in cystic fibrosis, but none has gained general acceptance. Many centres are naturally reluctant to consider thoracotomy in patients who have extensive pulmonary disease. Increasingly patients with cystic fibrosis are surviving into adult life, and in the future will present to thoracic physicians with this problem. A review of our experience in such patients over the last 15 years was made in an attempt to define a plan of management for future cases.

\section{Methods}

The case histories of 243 patients with cystic fibrosis who attended the clinic at the Brompton Hospital from September 1965 to April 1981 were analysed retrospectively (table 1 ). This represents $98.4 \%$ of all patients seen at this clinic, the notes of the remainder not being available. There were 134 males and 109 females, age range 13-48 years (mean 24.2 years). The diagnosis was established in each case on the basis of typical clinical findings, and a sweat sodium concentration of over $70 \mathrm{mmol}(\mathrm{mEq}) / \mathrm{l}$. The age and length of follow-up given for each patient refers to

Address for reprint requests: Dr A Penketh, Cardiothoracic Institute, Fulham Road, London SW3 6HP.
April 1981 for those still alive or to the date of death. Forced expiratory volume in one second $\left(\mathrm{FEV}_{1}\right)$ and forced vital capacity (FVC) were measured with a Vitalograph dry spirometer, and expressed as a percentage of predicted normal values on the basis of tables published by Cotes. ${ }^{6}$

Conservative management of pneumothorax in symptomless cases consisted of either close out- $\overrightarrow{\overrightarrow{0}}$ patient follow-up, if patients were otherwise well, or 3 observation in hospital with physiotherapy and antibiotics as necessary. Dyspnoea, cyanosis, pain, tension pneumothorax, or complete collapse of the lung were the main indications for active treatment. Surgical treatment consisted of open thoracotomy with $x$ either abrasion pleurodesis by means of a wire brush 욱 or pleurectomy at the discretion of the surgeon. Medical pleurodesis was performed by instillating sclerosing agents via an intercostal drain. A recurrence was defined as a pneumothorax occurring on the same 옥 side more than seven days after resolution of a previ- $\rightarrow$ ous pneumothorax.

The data have been analysed retrospectively and $N$ decisions about methods of treatment were made

Table 1 Incidence of pneumothorax in adults with cystic fibrosis 1965-81

\begin{tabular}{lccc}
\hline & Male & Female & Total \\
\hline No of patients & 134 & 109 & 243 \\
No with pneumothorax & 34 & 12 & 46 \\
Incidence of pneumothorax & $25.4 \%^{*}$ & $11 \%^{*}$ & $18.9 \%$ \\
\hline
\end{tabular}

*Significance of difference: $p<0.05$. 
according to views and circumstances at the time, rather than on the basis of a defined policy. There were some differences in the methods of treatment used for first episodes and for recurrences. In general, asymptomatic first episodes were managed conservatively and symptomatic ones by intercostal drainage initially, with recourse to surgery only if drainage was unsuccessful. Recurrent episodes tended to be treated more aggressively, and some symptomless patients were treated actively. Surgery was used as a first line of treatment for some patients with recurrent episodes.

\section{Results}

Forty-six patients (18.9\%), 34 male and 12 female, had experienced at least one episode of pneumothorax. The male-to-female ratio was 2.8:1. There is a predominance of men in adults with cystic fibrosis, ${ }^{4}$ and in our clinic the ratio is $1.22: 1$. The excess of males experiencing a pneumothorax is significant at the $5 \%$ level $\left(\chi^{2}\right.$ test, table 1$)$. Over half of the patients had more than one episode, the total being 106 , but only the 81 episodes seen at this hospital were used to compare the different methods of treatment. The methods used as the first line of treatment for each of these 81 episodes are compared in table 2. The mean duration of follow-up after the first pneumothorax was 51 months (range 1 month10 years). All but two patients had an FEV ${ }_{1}$ of less than $50 \%$ of the predicted normal value before their first episode of pneumothorax.

\section{Conservative management}

Thirty-one episodes initially had conservative management, four patients requiring further treatment owing to a deterioration in symptoms or an increase in size of the pneumothorax. One patient was admitted in respiratory failure with a small coincident pneumothorax and subsequently died. Twenty-six episodes resolved but in half of these cases the pneumothorax later recurred, with a mean interval of 10.8 months before the next episode.

\section{Intercostal drainage}

Forty-three episodes were treated by intercostal drainage - unsuccessfully in 11 , which required
Table 3 Prolonged intercostal drainage (>seven days)

\begin{tabular}{|c|c|c|}
\hline $\begin{array}{l}\text { Patient } \\
\text { No }\end{array}$ & $\begin{array}{l}\text { No of days } \\
\text { of drainage }\end{array}$ & Result \\
\hline $\begin{array}{l}1 \\
2 \\
3 \\
4 \\
5 \\
6 \\
6 \\
7 \\
8 \\
4 \\
4 \\
5\} \\
\text { epist } \\
\begin{array}{l}\text { Second } \\
\text { episode }\end{array}\end{array}$ & $\begin{array}{r}8 \\
9 \\
10 \\
10 \\
10 \\
13 \\
19 \\
25 \\
25 \\
25\end{array}$ & $\begin{array}{l}\text { Surgery } \\
\text { Resolved } \\
\text { Resolved } \\
\text { Surgery } \\
\text { Resolved } \\
\text { Surgery, died } \\
\text { Died } \\
\text { Died } \\
\text { Died } \\
\text { Surgery, died }\end{array}$ \\
\hline & & Mortality $50 \%$ \\
\hline
\end{tabular}

further treatment. Three patients died, one after 10 days of a persistent air leak, and two after 25 days each. Many patients had drains resited, and persistent air leaks were common. In 10 episodes a drain was left in situ for longer than seven days. Half of these patients died (table 3 ). In the successful cases drainage continued for an average of 5.1 days (range 1-9 days). Twenty-nine episodes resolved with intercostal drainage, but 16 later recurred $(55.2 \%)$. The mean interval before the next pneumothorax was 10.9 months.

\section{Surgery}

Twenty episodes of pneumothorax in 16 patients were treated surgically. There were five abrasion pleurodeses and 15 pleurectomies, which will be considered together. The mean duration of follow-up after surgery was 59 months compared with 51 months for all 46 patients with pneumothoraces. Thoracotomy was successfully performed in seven out of eight patients with an FEV 1 of under $25 \%$ of the predicted normal value before the pneumothorax and in 10 out of 12 with an FEV 1 of $25 \%$ or more. Severe airflow obstruction was not therefore a contraindication to surgery. In seven episodes surgery was the primary treatment and this group of patients did very well (table 2). All operations were successful and only two patients had recurrences, in both cases minor. These patients had all had a previous pneumothorax. A decision to operate was made quickly, within 48 hours of admission, and all patients had preoperative physiotherapy and intravenous antibiotics.

Table 2 Results of first-line method of treatment of 81 episodes of pneumothorax in 46 adults with cystic fibrosis.

\begin{tabular}{|c|c|c|c|c|c|}
\hline $\begin{array}{l}\text { Method of } \\
\text { treatment }\end{array}$ & $\begin{array}{l}\text { No of } \\
\text { episodes } \\
(n=81)\end{array}$ & $\begin{array}{l}\text { No }(\%) \\
\text { of deaths }\end{array}$ & $\begin{array}{l}\text { No }(\%) \\
\text { requiring further } \\
\text { treatment }\end{array}$ & $\begin{array}{l}\text { No }(\%) \\
\text { resolving initially }\end{array}$ & $\begin{array}{l}\text { No }(\%) \\
\text { of recurrences }\end{array}$ \\
\hline $\begin{array}{l}\text { Conservative } \\
\text { Intercostal drain } \\
\text { Surgery }\end{array}$ & $\begin{array}{r}31 \\
43 \\
7\end{array}$ & $\begin{array}{l}1(3 \cdot 2) \\
3(6 \cdot 9) \\
0\end{array}$ & $\begin{array}{l}4(12 \cdot 9) \\
11(25 \cdot 7) \\
0\end{array}$ & $\begin{array}{c}26(83 \cdot 9) \\
29(67 \cdot 4) \\
7(100)\end{array}$ & $\begin{array}{r}13(50) \\
16(55 \cdot 2) \\
2(28 \cdot 6)\end{array}$ \\
\hline
\end{tabular}


Thirteen operations were performed as a secondline treatment after failed intercostal drainage and three patients died in the immediate postoperative period. Two of these had experienced a stormy and prolonged preoperative period of intercostal drainage (table 3 ). The third patient had prolonged apnoea shortly after extubation.

\section{Medical pleurodesis with sclerosant agents}

Six patients were treated with talc or iodine as sclerosant agents, as an addition to intercostal drainage; in all of them the pneumothorax recurred.

\section{Recurrence rate and mortality}

Twenty-five patients $(54.3 \%)$ had more than one episode of pneumothorax, and nine had four or more. One patient suffered 11 separate episodes.

Seven patients $(15.2 \%)$ died as a direct consequence of a pneumothorax.

\section{Discussion}

The natural history of pneumothorax in adults with cystic fibrosis seen at the Brompton Hospital was reviewed by Knight and Batten. ${ }^{1}$ They found that the condition was related to low weight, but not to height. Pneumothorax occurred at any age, more commonly in the winter months. It occurred with equal frequency on the two sides, and was not related to prior steroid treatment. The most important association was with severe airflow obstruction, most patients having an $\mathrm{FEV}_{1}$ of less than $50 \%$ of the predicted normal value before developing a pneumothorax.

The frequency of spontaneous pneumothorax in children with cystic fibrosis is estimated at $2-7 \%$ by various authors. ${ }^{257}$ For example, in a population of mean age 14.4 years, a frequency of $3.8 \%$ was quoted by Boat et al. ${ }^{5}$ In our series the frequency of pneumothorax is $18.9 \%$ in a population of mean age 24.2 years. This compares with $16 \%$ reported in a survey of adults in the United States for which no mean age was quoted. ${ }^{4}$

Spontaneous pneumothorax in the normal population has an incidence of five per 100000 per year and is classically seen in young men. The male-to-female ratio is $5: 1$. The treatment has been extensively described ${ }^{89}$ and the recurrence rate after conservative treatment is $9-18 \%$ in different series, and after intercostal drainage $12-17 \%$.

In our series pneumothorax was more common in males than in females, and this difference between the sexes is significant $(p<0.05)$ despite the male predominance of cystic fibrosis in adults (table 1 ). The rate of recurrence was high, $50 \%$ after conservative treatment and $55 \%$ after intercostal drainage. Persistent air leaks were common and drains were often resited. The hazards of prolonged drainage in patients with cystic fibrosis are retention of secretions, exacerbation of infection, the impossibility of adequate physiotherapy, deteriorating respiratory function, and shattered morale.

Spontaneous pneumothorax in the normal population may be due to the rupture of subpleural blebs. Blebs were found at necropsy in $60 \%$ of patients with cystic fibrosis over the age of $10 .^{5}$ Apical blebs were found at operation in 26 out of 31 thoracotomies. ${ }^{7}$ Mucous plugs may form a check-valve obstruction in a bronchus leading to a rapid increase in pressure and rupture of a bleb. This plugging may also hinder subsequent expansion. The tendency for delayed resolution of pneumothorax in cystic fibrosis may also be related to the lack of compliance of the lungs, and perhaps to the abnormal cells in the visceral pleura noted by Dunnill. ${ }^{10}$

A more aggressive approach to the management of pneumothorax in cystic fibrosis with early thoracotomy has been recommended. ${ }^{371112}$ Luck et $a l^{3}$ reported three deaths in 30 operations on children with cystic fibrosis and recommended thoracotomy for a persistent air leak after 5-7 days. Stowe et al ${ }^{11}$ compared 17 patients treated by thoracotomy with 29 patients treated in other ways. The former group had a shorter stay in hospital, a lower recurrence rate, and a similar survival rate. Rich et al treated 31 episodes of pneumothorax with thoracotomy and pleural abrasion. There was only one death and one recurrence, and they recommended open thoracotomy as the primary treatment of pneumothorax in cystic fibrosis. They considered that the risk of a subsequent contralateral episode was so high that they performed two prophylactic abrasions. In our series the patients treated surgically had a similar death rate and length of survival to the whole group of 46 cases, and had a substantially lower recurrence rate. Thoracotomy was successful in those with severe airflow obstruction. We conclude that thoracotomy is a safe and effective form of treatment of pneumothorax in cystic fibrosis, and can be recommended as a primary mode of treatment.

Our present policy of management of pneumothorax in cystic fibrosis is to observe a small $\stackrel{\sim}{\circ}$ first, asymptomatic pneumothorax, either in hospital $N$ or by close out-patient follow-up, and to treat concurrent exacerbations of infection vigorously. Most of these episodes will resolve. A symptomatic first pneumothorax is treated by intercostal drainage, $\stackrel{\varrho}{C}$ adequate analgesia, physiotherapy, and antibiotics. We regard a persistent air leak at seven days as an absolute indication for surgery as intercostal drainage after this time is unlikely to be successful, and $\underset{\mathbb{D}}{\stackrel{D}{D}}$ prolonged drainage has a poor prognosis. Early $\frac{\Omega}{\mathbb{D}}$ communication between physicians and surgeons 
after admission of such patients is essential to successful management.

In second or subsequent episodes of pneumothorax the risk of a further recurrence may justify surgical management to prevent a later episode when the patient's disease has progressed. We have insufficient data to compare the merits of pleurodesis and pleurectomy. At this hospital we prefer abrasion pleurodesis to pleurectomy, as it seems to cause less bleeding and less restriction of chest wall movement postoperatively.

We are most grateful to $\mathrm{Mr}$ M Paneth and Mr SC Lennox, who operated on these patients. Miss Sally Hockley kindly prepared this manuscript. AP is supported by the Frances and Augustus Newman Foundation.

\section{References}

' Knight RK, Batten JC. Pneumothorax in cystic fibrosis. In: Sturgess JM, ed. Proceedings of the eighth international conference on cystic fibrosis, Toronto 1980. 376-81.

${ }^{2}$ Lifschitz MI, Bowman FO, Denning CR, Wylie RH.
Pneumothorax as a complication of cystic fibrosis. Am J Dis Child 1968;116:633-40.

${ }^{3}$ Luck SR, Raffensperger JG, Sullivan HJ, Gibson LE. Management of pneumothorax in children with chronic pulmonary disease. J Thorac Cardiovasc Surg 1977;74:834-9.

${ }^{4}$ di Sant'Agnese PA, Davis PB. Cystic fibrosis in adults. Am J Med 1979;66:121-32.

${ }^{5}$ Boat TF, di Sant'Agnese PA, Warwick WJ, Handwerger SA. Pneumothorax in cystic fibrosis. JAMA 1969;209:1498-504.

${ }^{6}$ Cotes JE. Lung function. 3rd ed. Oxford: Blackwell Scientific Publications, 1975.

${ }^{7}$ Rich HR, Warwick WJ, Leonard AS. Open thoracotomy and pleural abrasion in the treatment of spontaneous pneumothorax in cystic fibrosis. $J$ Pediatr Surg 1978;13:237-42.

${ }^{8}$ Stradling P, Poole G. Conservative management of spontaneous pneumothorax. Thorax 1966;21:145-9.

${ }^{9}$ Ruckley CV, McCormack RJM. The management of spontaneous pneumothorax. Thorax 1966;21:139-44.

${ }^{10}$ Dunnill MS. Metaplastic changes in the visceral pleura in a case of fibrocystic disease of the pancreas.J Path Bact 1959;77:299-302.

"Stowe SM, Boat TF, Mendelsohn $\mathrm{H}$ et al. Open thoracotomy for pneumothorax in cystic fibrosis. $A m$ Rev Respir Dis 1975;111:611-71.

${ }^{12}$ Mitchell-Heggs PF, Batten JC. Pleurectomy for spontaneous pneumothorax in cystic fibrosis. Thorax 1970;25:165-71. 